\title{
Relapsing depression in paramedian thalamic infarctions
}

\author{
R.W. Baumgartner, T. Landis and M. Regard \\ Department of Neurology, University Hospital, Zürich, Switzerland \\ Correspondence to: R.W. Baumgartner, Department of Neurology, Inselspital Bern, \\ CH-3010 Bern, Switzerland
}

\begin{abstract}
Depression has recently been associated with lesions in the CNS, particularly with large infarctions in the cerebral hemispheres. We report a patient in whom two episodes of acute depression were related to relapsing paramedian thalamic infarctions, which were accompanied by additional transient mild neuropsychological deficits, hypersomnia and a discrete sensory disturbance of the left face. Thalamic infarctions have been shown to mimic a variety of higher functional deficits, such as aphasias, apraxias and attentional disorders, traditionally associated with hemispheric strokes. We conjecture that the paramedian thalamic infarctions observed in our patient have in a similar manner been responsible for the transient depression.
\end{abstract}

Keywords: Depression - Infarction - Stroke - Thalamus

\section{INTRODUCTION}

Although Bleuler (1916) long ago expressed the view that "there is indubitably a primary inclination toward depression and anxious interpretations of experience, and often toward oppressive feelings, that is quite frequently a direct consequence of disturbances of blood circulation of the brain", depression has generally been viewed as a disorder reactive to the consequences of CNS injury, than directly caused by it. Only recently has depression been found to be preferably linked to strokes in specific vascular territories of the cerebral hemispheres (e.g. Folstein et al., 1977; Robinson et al., 1984; Sinyor et al., 1986; Landis and Regard, 1988). Thalamic strokes, on the other hand, have in recent years increasingly been shown to produce neuropsychological deficits, such as aphasia, apraxia or attentional disorders, previously thought to occur only subsequent to lesions in the cerebral hemispheres at specific sites (e.g. Metter et al., 1981; Wallesch et al., 1983; Graff-Radford et al., 1985; De Renzi et al., 1986; Skyhoj et al., 1986; Perani et al., 1987; Stuss et al., 1988; Vallar et al., 1988; Schnider et al., 1991). Patients with paramedian thalamic infarction usually show impairment of consciousness, hypersomnia, neuropsychological deficits and ocular motor disorders affecting especially the vertical gaze (Castaigne et al., 1981; Gentilini et al., 1987; Bogousslavsky et al., 1988). Motor weakness, ataxia, delayed abnormal movements and hypoaesthesia involving the upper part of the body may also occur. We report a patient with recurrent paramedian thalamic infarctions, who developed a relapsing depression of acute onset.

\section{CASE REPORT}

During recovery from viral pneumonia, this 47-year old woman noted an acute change of personality with depressive mood, anxiety, phobic attacks, slowed thinking, inability to concentrate, decreased energy, withdrawal from usual activities, diminished sexual interest, reduced appetite and constipation. She also had problems with learning and memory, and an increased total sleep time of about $2 \mathrm{~h}$. With the exception of a history of cigarette smoking (39 packyears) and a daily consumption of about $25 \mathrm{~g}$ alcohol over the last 20 years, her medical and psychiatric history were unremarkable. Three months later she was given a tetracyclic antidepressant (maprotilin hydrochloric) and a benzodiazepine (lorazepam) and 7 months later neurological examination was normal with the exception of a hypaesthetic area over the left cheek. Neuropsychological examination revealed mild disturbances in learning and recall, more marked for verbal than for figural material and mildly impaired concept identification and interference suppression. Parasagittal and axial cerebral MRI (1,5 Tesla; spin echo; slice thickness $8 \mathrm{~mm}$ ) showed in T1- and T2-weighted images (relaxation time 510 and $2050 \mathrm{~ms}$, respectively), echo time 16 and $100 \mathrm{~ms}$, respectively) a lesion in the perfusion territory of the right paramedian thalamic arteries (Fig. 1a, b). The maximal infarcted volume was between 101 and $120 \mathrm{~mm}^{3}$. Pulsedwave Doppler and Duplex sonography of the carotid, vertebral and subclavian arteries and transcranial Doppler examination of the intracranial vertebral, basilar, posterior, middle and anterior cerebral arteries and carotid

Behavioural Neurology . Vol 5 . 1992 
a

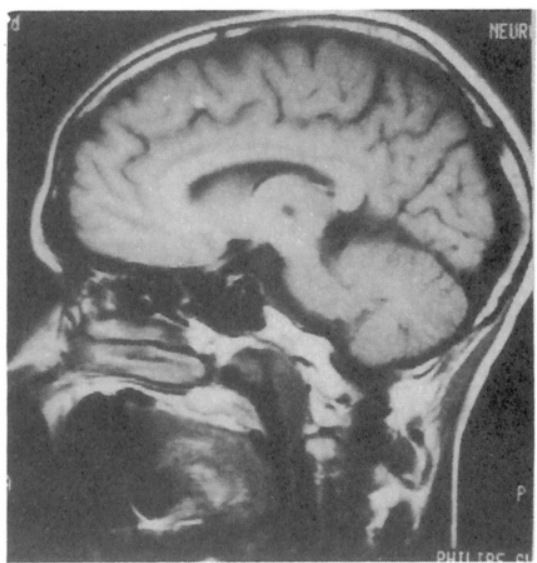

C

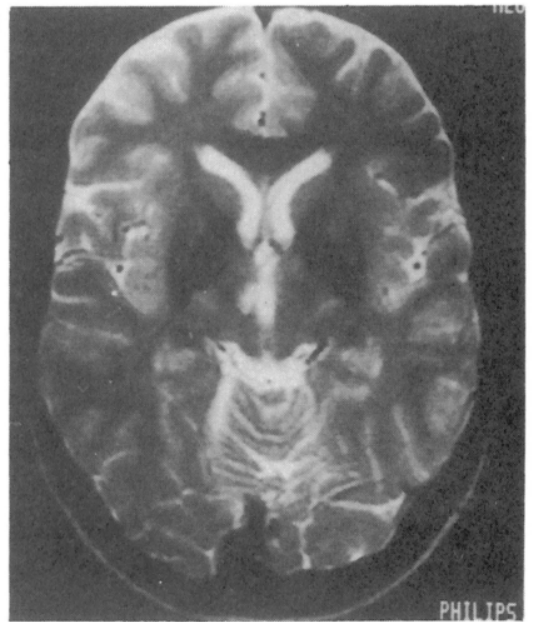

e

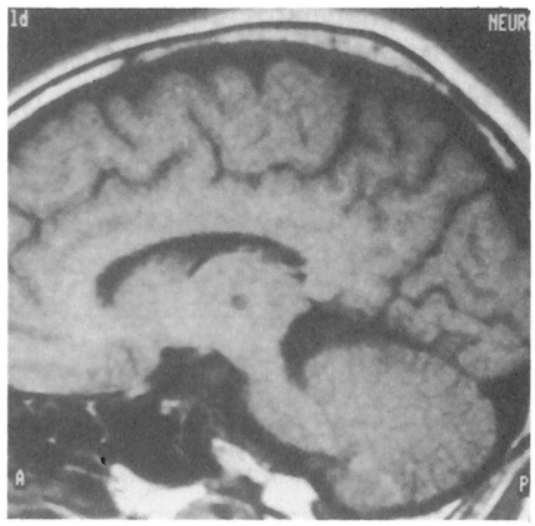

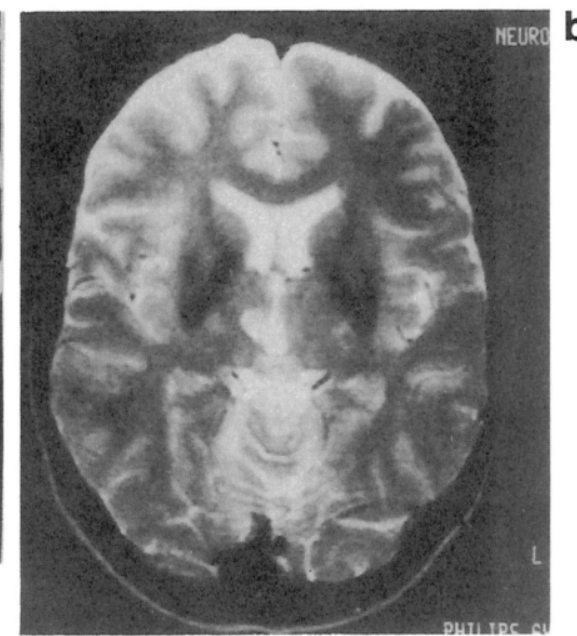
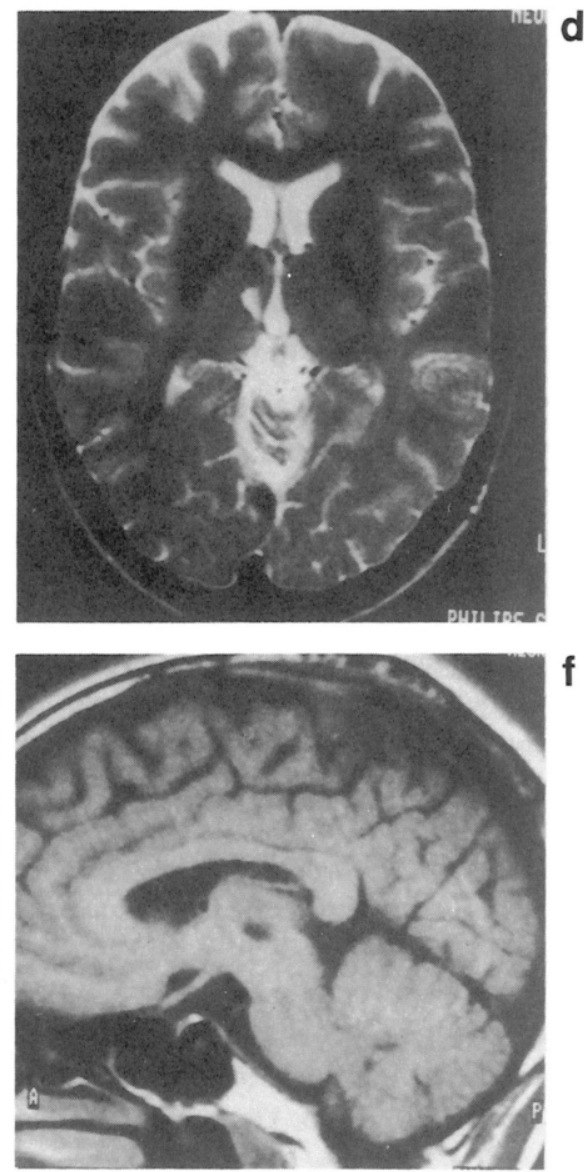

FIG. 1a-f. Parasagittal (a, e, f; T1W1) and axial (b, c, d; T2W1) cerebral MRI 9 months after the first $(a, b)$ and 3 months after the second $(c-f)$ stroke. For details see text.

siphons were normal. An electroencephalogram showed beta and episodic bitemporal theta activity with some interspersed alpha transients. Except for mild hypercholesterolemia, all laboratory tests including CSF examination were normal. In the following months the patient subjectively recovered completely, but 12 months later the same symptoms recurred acutely. Neurological examination showed again only an area of diminished sensation over the left face. Neuropsychological examination demonstrated unchanged mild memory disturbances for verbal and figural material, a marked reduction in figural fluency (Regard et al., 1982) but an excellent verbal fluency. Para-

130 Behavioural Neurology . Vol 5 . 1992 
sagittal and axial cerebral MRI (Fig. 1c-f; 1,5 Tesla; spin echo) disclosed an increased maximal infarcted volume of the above-mentioned paramedian thalamic lesion to 154$170 \mathrm{~mm}^{3}$ in $\mathrm{T} 1$ - and T2-weighted images (slice thickness 5 $\mathrm{mm}$ and $4 \mathrm{~mm}$, relaxation time 500 and $2000 \mathrm{~ms}$, echo time 15 and $100 \mathrm{~ms}$, respectively). ECG and echocardiogram were normal, as was the coagulation status, anti-nuclearantibody-, anti-DNA and anti-cardiolipin-titres were negative.

About 10 months after the second stroke the patient was free of any symptoms.

\section{DISCUSSION}

Our patient suffered from two infarctions in the perfusion territory of the right paramedian thalamic arteries (posterior thalamo-subthalamic artery, retromamillary or thalamo-perforate pedicle (Foix and Hillemand, 1925; Percheron, 1976; Bogousslavski et al., 1988)). Clinically the infarctions presented with hypersomnia, a discrete left facial sensory impairment and mild disturbances of memory and frontal lobe functions, such as impaired fluency, concept identification and interference suppression. Although this clinical picture corresponded to the paramedian thalamic infarctions as seen in MRIs, the relapsing profound depression of acute onset does not. The temporal course of these severe episodes of depression of acute onset in conjunction with neurological symptoms of a paramedian thalamic infarction makes it likely that the infarctions were the cause of the depression. Depression as a direct consequence of hemispheric strokes has gained acceptance in recent years (Robinson et al., 1984; Sinyor et al., 1986). Various cerebral structures have previously been associated with depression. These include: frontal lobe structures, in particular left frontal lobe damage (Robinson et al., 1984), right posterior structures, in particular those affected by strokes in the territory of the right posterior cerebral artery (Regard and Landis, 1988) and temporal lobe structures, in particular in temporal lobe epilepsy, possibly more frequent with a right hemispheric focus (Mendez et al., 1986; for review see Taylor, 1989). Lesions of the intralaminar and dorsal median thalamic nuclei destroy important relay stations between these structures, and should, therefore, theoretically have the potential to produce similar symptoms as those observed with hemispheric lesions. In fact, thalamic lesions have produced a number of symptoms commonly associated with cortical lesions, such as aphasia, apraxia and attentional disorders. Such far-reaching effects were long ago labelled "diaschisis" (von Monakow, 1914) and are thought to be a phenomenon of transient disconnection. If, similar to other higher cognitive disorders, mood disorders such as depression depend upon the intactness of thalamocortical connections, it is conceivable that their disconnec- tion may lead not only to higher cognitive disturbances usually associated with the respective cortical structures, but also to corresponding disturbances in mood. We thus conjecture that, in our patient, the lesion of the right paramedian thalamic structures may have led to acute depression in a manner similar to the diaschisis phenomena of cognitive disturbances.

\section{REFERENCES}

Bleuler E (1916) Lehrbuch der Psychiatrie. Springer, Berlin. Bogousslavsky J, Regli F and Uske A (1988) Thalamic infarcts: clinical syndromes, etiology, and prognosis. Neurology, 38, 837-848.

Castaigne P, Lhermitte F, Buge A, Escourolle R, Hauw JJ and Lyon-Caen O (1981) Paramedian thalamic and midbrain infarcts: clinical and neurological study. Annals of Neurology, 10, 127-148.

De Renzi E, Faglioni P, Scarpa M and Crisi G (1986) Limb apraxia in patients with damage confined to the left basal ganglia and thalamus. Journal of Neurology, Neurosurgery, and Psychiatry, 49, 1030-1038.

Foix C and Hillemand $\mathrm{P}(1925)$ Les syndromes de la région thalamique. Presse Medicale, 1, 113-117.

Folstein MF, Maiberger R and McHugh PR (1977) Mood disorder as a specific complication of stroke. Journal of Neurology, Neurosurgery, and Psychiatry, 40, 1018-1020.

Gentilini M, De Renzi E and Crisi G (1987) Bilateral paramedian thalamic artery infarcts: report of eight cases. Journal of Neurology, Neurosurgery, and Psychiatry, 30, 900-909.

Graff-Radford NR, Damasio H, Yamada T, Eslinger PJ and Damasio AR (1985) Nonhemorrhagic thalamic infarction. Brain, 108, 485-516.

Landis T and Regard M (1988) Lateralität und Depression: eine Untersuchung an Patienten mit Insulten im Versorgungsgebiet der A. cerebri posterior. In: Psychiatrie des rechten und linken Gehirns (Hrsg G Oepen). Deutscher Aerzte, Köln.

Mendez MF, Cummings JL and Benson F (1986) Depression in epilepsy. Archives of Neurology, 43, 766-770.

Metter EJ, Westerlain CG, Kuhl DE, Hanson WR and Phelps ME (1981) 18-FDG positron emission computed tomography in a study of aphasia. Annals of Neurology, 10, 173-183.

von Monakow C (1914) Die Lokalisation im Grosshirn und der Abbau der Funktion durch kortikale Herde. J.F. Bergmann, Wiesbaden.

Perani D, Vallar G, Cappa S, Messa C and Fazio F (1987) Aphasia and neglect after subcortical stroke. A clinical/cerebral perfusion correlation study. Brain, 110, 1211-1229.

Percheron G (1976) Les artères du thalamus humain. II. Artères et territoires thalamiques paramédians de l'artère basilaire communicante. Revue Neurol, 132, 309-324.

Regard M, Strauss E and Knapp P (1982) Children's production on verbal and non-verbal fluency tasks. Perceptual and Motor Skills, 55, 839-844.

Robinson RG, Kubos KL, Starr LB, Rao K and Price TR (1984) Mood disorders in stroke patients. Brain, 107, 81-93.

Schnider A, Landis T and Rösler HR (1991) Ideomotor apraxia in left thalamic hemorrhage: discrepancy between clinical course and SPECT. Behavioural Neurology, 4, 15-24.

Sinyor D, Jacques P, Kaloupek DG, Becker R, Goldenberg M and Coopersmith $H$ (1986) Postroke depression and lesion location. Brain, 109, 537-546. 
Skyhoj Olsen T, Bruhn P and Öberg RG (1986) Cortical hypoperfusion as a possible cause of "subcortical aphasia". Brain, 109, 393-410.

Stuss DT, Guberman A, Nelson R and Larochelle S (1988) The neuropsychology of paramedian thalamic infarction. Brain Cognition, 8, 348-378.

Taylor DC (1989) Affective disorders in epilepsies: a neuropsychiatric review. Behavioural Neurology, 2, 49-68.
Vallar G, Perani D, Cappa S, Messa C, Lenzi GL and Fazio F (1988) Recovery from aphasia and neglect after subcortical stroke: neuropsychological and cerebral perfusion study. Journal of Neurology, Neurosurgery, and Psychiatry, 51, 1269-1276.

Wallesch CW, Kornhuber HH, Kunz T and Brunner RJ (1983) Neuropsychological deficits associated with small unilateral thalamic lesions. Brain, 106, 141-152. 


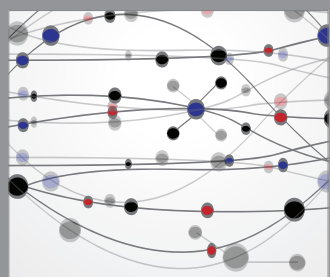

The Scientific World Journal
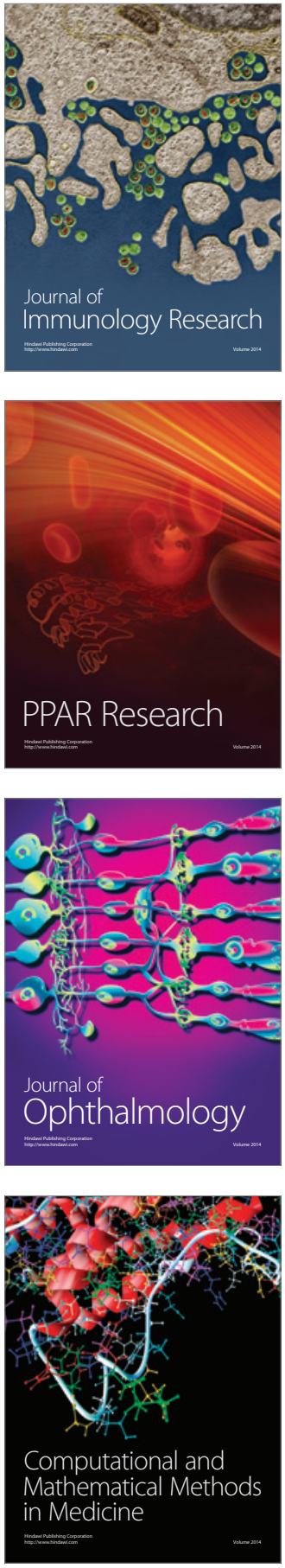

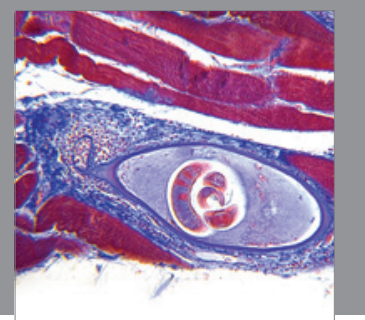

Gastroenterology

Research and Practice
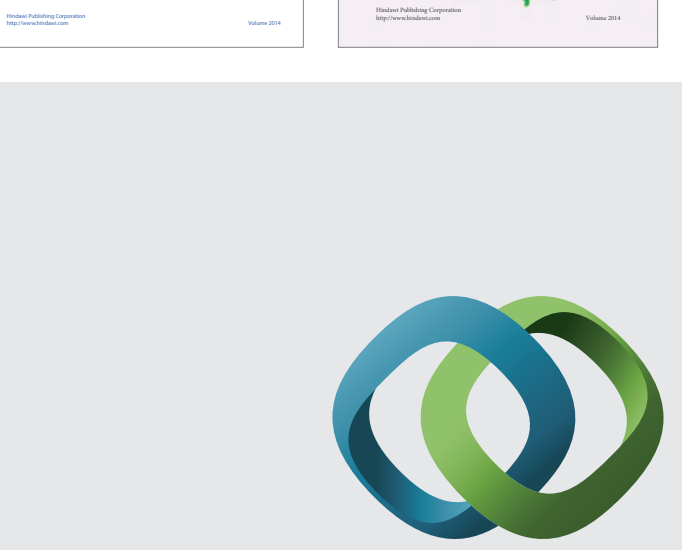

\section{Hindawi}

Submit your manuscripts at

http://www.hindawi.com
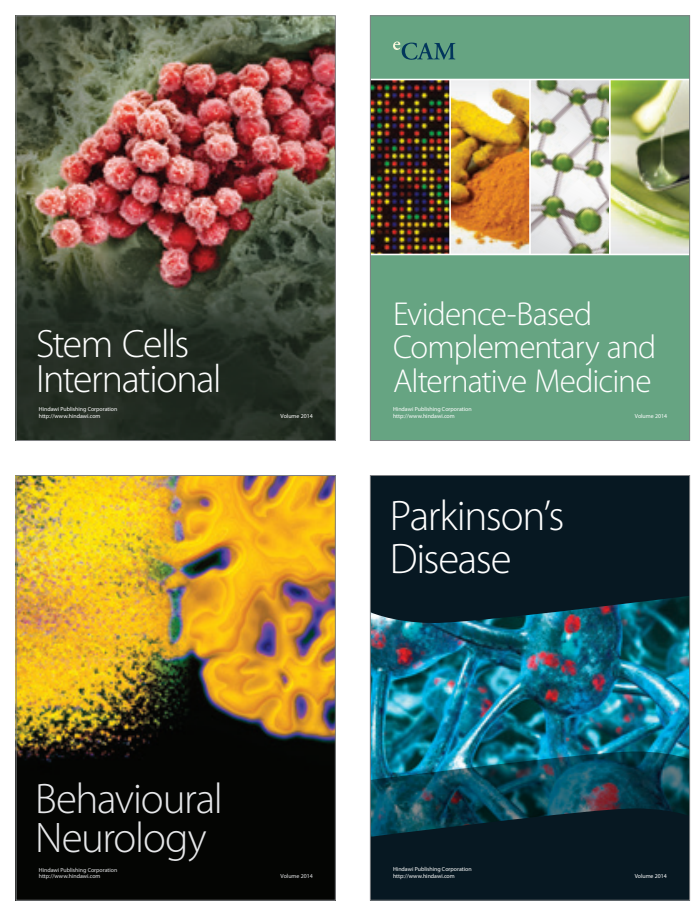

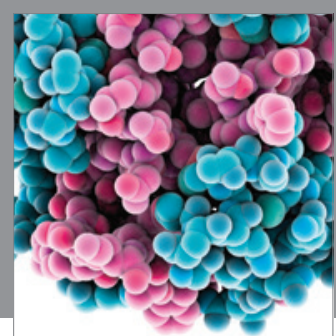

Journal of
Diabetes Research

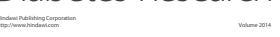

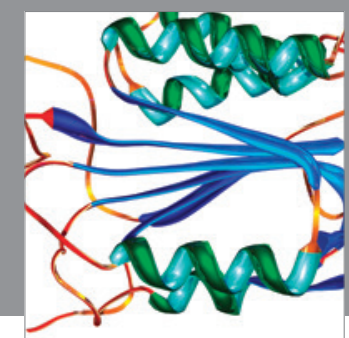

Disease Markers
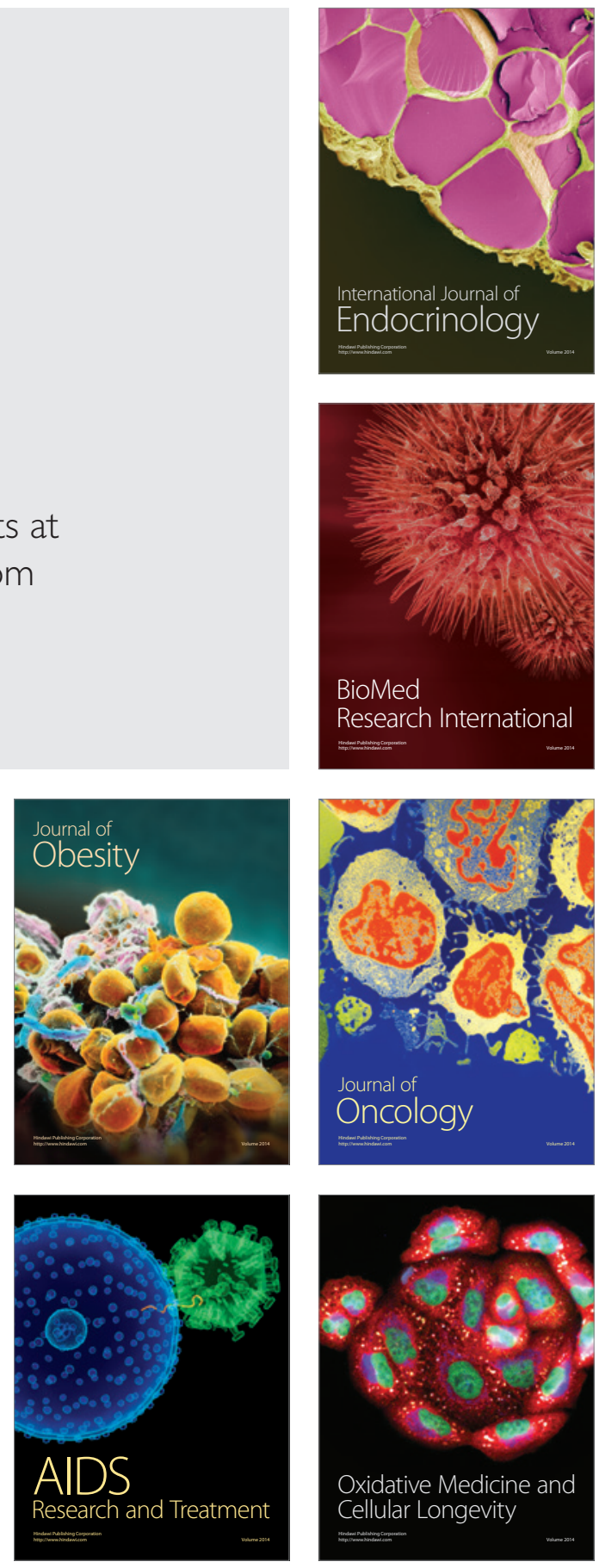